\title{
Transition from Pits to Stress Corrosion Cracking of SAE 4120 Steel in Simulated Oilfield Environment
}

\author{
Bingying Wang ${ }^{1, *}$, Yige Liu ${ }^{1}$, Zhiwei Gao ${ }^{1}$, Tongle Zhang ${ }^{1}$, Feng Yang $^{2}$, Shouqin Li ${ }^{2}$ \\ ${ }^{1}$ School of Materials Science and Engineering, China University of Petroleum (East China), Qingdao \\ 266580, China \\ ${ }^{2}$ Dongxin Oil Production Plant, Shengli Oilfield Company, SINOPEC, Dongying 257094, China \\ *E-mail: tdwby2004@126.com
}

doi: $10.20964 / 2021.02 .25$

Received: 30 June 2020 / Accepted: 26 October 2020 / Published: 31 December 2020

\begin{abstract}
SAE 4120 steel, the main steel material for sucker tools in oilfield production system, is usually subjected to the combined effects of stress and corrosive media in the oilfields corrosion environment containing $\mathrm{CO}_{2}$. This work presented the evolution of pits and stress corrosion cracks in the steel while exposing to stress and corrosion medium. In the simulated oilfield environment, the four-point bending high temperature and high pressure stress corrosion test was carried out to investigate the evolution process of pits and stress corrosion cracks. The morphologies of pits and cracks were characterized by scanning electron microscopy to study the process of crack initiation and growth. In addition, the stress and strain distribution of corrosion pits was described using ABAQUS finite element analysis software to qualitatively analyze the vulnerable location of crack origin. The results exhibited that corrosion pits originated from inclusions, while the SCC initiated from the bottom of secondary corrosion pits and extended along the depth direction of SAE 4120 steel in the simulated oilfield environment with in water saturated with $\mathrm{CO}_{2}$. Finite Element Analysis showed that the maximum values of stress and strain were located at corrosion pits bottom. The existing secondary corrosion increased the degree of stress concentration, and the bottom of the secondary corrosion pits was the sensitive position of SCC.
\end{abstract}

Keywords: SAE 4120 steel; Four-point bending test; Pitting corrosion; Stress corrosion crack; Finite element analysis

\section{$\underline{\text { FULL TEXT }}$}

(C) 2021 The Authors. Published by ESG (www.electrochemsci.org). This article is an open access article distributed under the terms and conditions of the Creative Commons Attribution license (http://creativecommons.org/licenses/by/4.0/). 